\title{
A new questionnaire for the repeat of the first stage of the European Community Respiratory Health Survey: a pilot study
}

\author{
R. de Marco*, M.E. Zanolin*, S. Accordini*, D. Signorelli*, A. Marinoni**, M. Bugiani', \\ V. Lo Cascio ${ }^{++}$, R. Woods $\$$, P. Burney ${ }^{\#}$, on behalf of the ECRHS
}

A new questionnaire for the repeat of the first stage of the European Community Respiratory Health Survey: a pilot study. R. de Marco, M.E. Zanolin, S. Accordini, D. Signorelli, A. Marinoni, M. Bugiani, V. Lo Cascio, R. Woods, P. Burney, on behalf of the ECRHS. C ERS Journals Ltd 1999.

ABSTRACT: In the early 1990s a multicentre survey on asthma was performed on the young adult population (European Community Respiratory Health Survey - ECRHS). This study is to be repeated in order to estimate changes in the prevalence of asthmalike symptoms during the last decade and to assess the social and economic costs of the disease and their variations among countries.

The self-administered questionnaire devised for this purpose is a two-page questionnaire. The first page contains the same items as those used in the first survey with four additional questions related to: 1) the frequency and severity of asthma attacks; 2) the presence of chronic bronchitis; 3) smoking habits; and 4) a visual analogue scale assessing perception of outdoor pollution. The second page aims to collect information regarding the direct and indirect costs of asthma. The influence of the length of the questionnaire on the response rate was assessed in a pilot study in Italy. Two random samples of 150 subjects received either the one-page questionnaire (first page) or the two-page questionnaire. The response rate was compared with that obtained from the first postal wave in the 1991-1992 survey.

Although the response rate was unchanged when using the one-page questionnaire $(45 \%$ versus $45 \%)$, it decreased by $7 \%$ when the two-page questionnaire was used $(38 \%$ versus $45 \%)$.

On the basis of these results, no problem should arise if four more questions are added to the one-page questionnaire. The slight reduction in the response rate of the two-page questionnaire is worrying but could be corrected by the use of telephone interviews. Eur Respir J 1999; 14: 1044-1048.
*Cattedra di Statistica Medica, Università di Verona, Verona, ${ }^{* *}$ Dipartimento di Scienze Sanitarie Applicate e Psico-comportamentali, Università di Pavia, Pavia, Istituto di Fisiopatologia Respiratoria, Dispensario di Igiene Sociale, Torino, ${ }^{++}$Istituto di Semeiotica e Nefrologia Medica, Università di Verona, Verona, Italy. ${ }^{*}$ Dept of Epidemiology and Preventive Medicine, Monash Medical School, Alfred Hospital, Prahran, Victoria, Australia. "Dept of Public Health Sciences, King's College, London, UK.

\section{Correspondence: R. de Marco \\ Istituto di Igiene \\ Cattedra di Statistica Medica \\ Istituti Biologici II \\ Strada le Grazie 8 \\ 37134 Verona \\ Italy \\ Fax: 39045505357}

Keywords: Asthma costs asthma epidemiology asthma questionnaire

Received: December 311998 Accepted after revision June 261999
The first stage of the European Community Respiratory Health Survey (ECRHS) provided standardized and comparable information regarding the prevalence of asthma, of asthma-like symptoms and of use of asthma drugs in a wide range of centres in the market economies in 19911992 [1-4]. Since then, International Guidelines on asthma management and prevention have been published and disseminated, possibly increasing the accuracy of asthma diagnosis and treatment.

There is now good evidence that the prevalence of asthma has risen significantly in both children and adults over the last two decades [5-7]. Indication of a birth cohort effect on asthma prevalence also emerged from further analysis of stage 2 ECRHS data (J. Sunyer, personal communication). A repeat of stage 1 of the ECRHS would make it possible to assess the extent of the changes in asthma prevalence in the young adult population during the last decade. It would also clarify whether or not the changes are the result of changes in diagnostic habits or in incidence of the disease.

Furthermore, bronchial asthma implies a high consumption of health and social resources in industrialized countries $[8,9]$. High variability in expenditure has been reported, which results from variability in management of the disease as well as in its prevalence [10-13]. Hence, it will be of interest, in the repeat of stage 1 , to evaluate the social and economic burden of asthma, its variation among countries and the main determinants of the costs of the disease.

The goals of the repeat of stage 1 are: 1) to describe the changes in the prevalence of asthma-like symptoms since the first survey and their variations among countries; 2) to describe variations in the prevalence of diagnosed asthma, the severity of asthma and chronic bronchitis, and potential risk factors (smoking and outdoor pollution) across and within countries; and 3) to describe variations in direct and indirect costs of asthma among and within countries (optional).

For these purposes, a new questionnaire to be used in the ECRHS stage 1 repeat has been designed, with the addition of new questions to the first questionnaire. The influence of the length of the questionnaire on response rate has been tested in a pilot study in Italy.

\section{Materials and methods}

Study design (European Community Respiratory Health Survey stage 1 repeat)

The repeat of stage 1 will follow the same protocol as used in the first stage of the survey in 1991-1992, which has been 
reported elsewhere $[14,15]$. Briefly, a representative sample of 20-44 yr-old males and females (ratio 1:1) will be randomly selected from the list of residents of the same geographic administrative areas as used in the first study. The initial sample size will comprise $\geq 3,000$ subjects.

The questionnaire will be sent to each subject up to three times in the case of nonresponse. A telephone interview will follow, if necessary, to obtain reliable response rates.

\section{Questionnaires}

Two versions of the questionnaire were used for the pilot study.

The one-page questionnaire. This was aimed at assessing respiratory symptoms and potential risk factors. This is made up of the same items as used in the first study [14] with additional questions on severity and frequency of asthma attacks, the presence of chronic bronchitis, smoking habits and a visual analogue scale regarding the subjective impact of outdoor pollution (table 1).

In particular, question 7, on "ever asthma", was taken from the long questionnaire used in ECRHS stage 2 [14]. Question 8, on chronic bronchitis was according to European guidelines [16]; question 9, on smoking habits, is a slightly modified version taken from the International Union against Tuberculosis and Lung Disease questionnaire [17]
The visual analogue scale (item 10) on outdoor pollution was taken from the Swiss Study on Air Pollution and Lung Disease in adults questionnaire [18]. This scale was validated in a previous study showing a strong correlation between subjective perception and the real degree of pollution [19].

The two-page questionnaire. This includes an additional page aimed at measuring the direct and indirect costs of asthma, health care utilization and compliance with treatment (table 2). This page is only completed by subjects reporting asthma-like symptoms. In particular, questions 11 and 12 refer to the indirect costs of the disease, question 13 to consulting a doctor or undergoing laboratory tests, questions 14 and 15 to the type of asthma treatment and compliance, and questions 16 and 17 to the history of hospitalization due to asthma symptoms.

\section{Pilot study}

The pilot study was performed in the three Italian centres already involved in the first stage of the ECRHS. An overall random sample of 300 subjects, stratified by sex, and aged 20-44 yrs, was selected from the national health service lists. Each version of the questionnaire was posted to a random subsample of 150 people. The study was completed 6 weeks after posting.

Table 1. - The one-page questionnaire as a modified form of the screening questionnaire of the first stage of the European Community Respiratory Health Survey

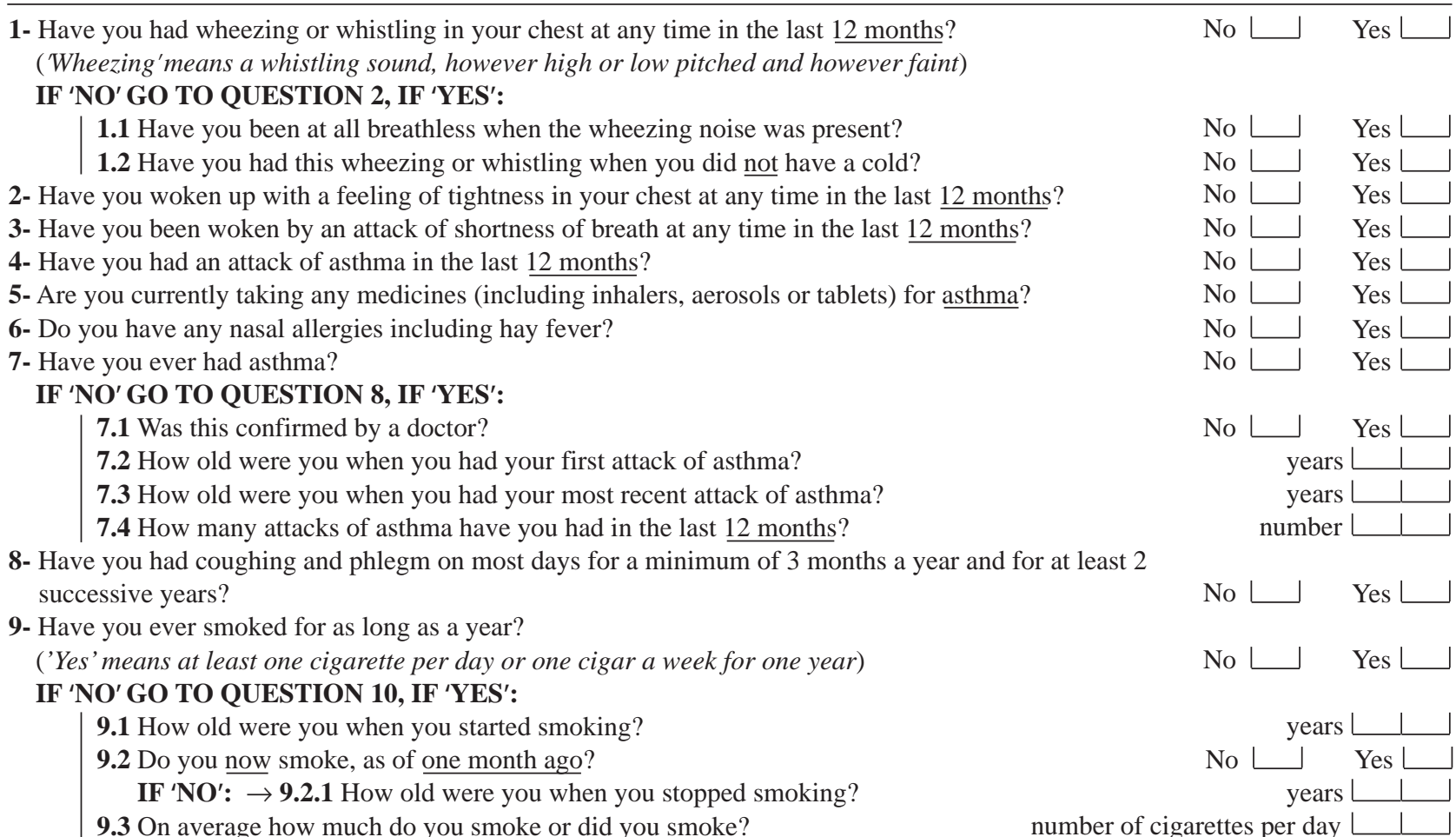

10- How much are you annoyed by outdoor air pollution (e.g. the smell of traffic, industry, etc.) at your present home if you keep the windows open? (indicate the degree of annoyance according to the following scale)

Does not disturb at all

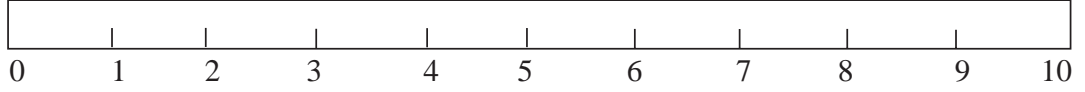


Table 2. - The added page of the two-page questionnaire to be filled in only by subjects with asthma symptoms

IF YOU HAVE ANSWERED 'YES' TO THE QUESTIONS ABOUT ASTHMA (No. 4 or 5 or 7), WHEEZING (No. 1) OR SHORTNESS OF BREATH (No. 3), PLEASE ANSWER THE FOLLOWING QUESTIONS:

11- If you are currently employed, have you lost any days of work because of your asthma, wheezing or shortness of breath in the last 12 months? $\quad$ No $L$ Yes $\downarrow-$ IF 'YES': $\rightarrow$ how many days?

12- Whatever your working situation, have there been any days when you have had to give up other activities (e.g. looking after children, the housework, studying) because of your asthma, wheezing or shortness of breath in the last 12 months?
No L _ Yes L _ _
IF 'YES':
$\rightarrow \quad$ how many days, on average, every month?

13- Have you been seen by a doctor because of your asthma, wheezing or shortness of breath, in the last 12 months?

\section{IF 'NO' GO TO QUESTION NUMBER 14, IF 'YES':}

Because of your asthma, wheezing or shortness of breath, in the last 12 months:

13.1 have you been seen by a general practitioner?

No $\downarrow$ Yes $\downarrow$ IF 'YES': $\quad \rightarrow \quad$ how many times?

13.2 have you been to see a specialist (chest physician, allergy specialist, internal medicine specialist, ENT doctor)?

$$
\text { No } \downarrow \text { Yes } ᄂ \quad \text { IF 'YES': } \rightarrow \quad \text { how many times? }
$$

13.3 have you had any clinical or laboratory tests?

IF 'YES': $\quad \rightarrow \quad$ specify the number of each type of clinical or laboratory test inside the squares:
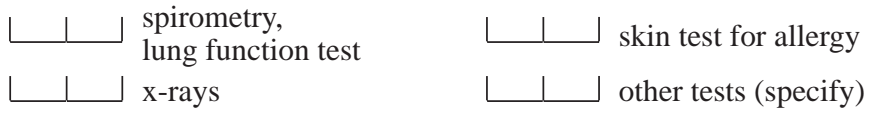

blood test for allergy

14- Have you used any medicines (including inhalers, aerosols or tablets) for asthma in the last 12 months?

IF 'YES': $\quad \rightarrow \quad \mathbf{1 4 . 1}$ Have the medicines been prescribed:

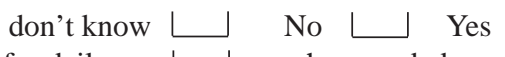

for daily use

when needed

15- If you are prescribed medicines for your breathing, do you normally take:

all of the medicine $L \quad$ most of the medicine $\downarrow \quad$ some of the medicine $L \downarrow$ none of the medicine

16- Have you visited a hospital casualty department or emergency room because of your asthma, wheezing or shortness of breath in the last 12 months?

No $\downarrow$ Yes $\downarrow \quad$ IF 'YES': $\rightarrow$ how many times?

17- Have you spent at least one night in hospital because of your asthma, wheezing or shortness of breath in the last 12 months?

No $\downarrow$ Yes $L \quad$ IF 'YES': $\rightarrow \quad$ how many times? $L$

IF 'YES': $\quad \rightarrow \quad$ specify the number of days spent in the following wards:

internal medicine, pneumology, general medicine, respiratory medicine

intensive care unit

rehabilitation

ENT: ear, nose and throat.

The response rates of the pilot study were compared with those obtained in Italy after the first posting of the screening questionnaire in the ECRHS survey carried out in 1991-1992 [20]. Differences in response rates were tested using the chi-squared statistic.

The expected number of responders, when using the two-page questionnaire in the new survey, was computed using the following equation:

$$
\mathrm{Ei}=\mathrm{Ni} \times \mathrm{Ri} \times(1-\Delta \mathrm{x}),
$$

where $\mathrm{Ei}$ is the expected number of responders at the ith postal wave $(\mathrm{i}=1,2,3), \mathrm{Ni}$ is the number of people contacted in the ith postal wave (number of subjects contacted in the 1 st postal wave $=3,000)$, $\mathrm{Ri}$ is the response rate to the ith postal wave in the first study in 1991-1992 and $\Delta \mathrm{x}$ the relative decrease in the response rate estimated in the pilot study and assumed to be constant in all postal waves. $\Delta \mathrm{x}=\left(\mathrm{P}_{1} \%-\mathrm{Pp} \%\right) / \mathrm{P}_{1} \%$, where $\mathrm{P} 1 \%$ is the response rate obtained at the first contact in the 1991-1992 survey and $\mathrm{Pp} \%$ is the response rate obtained in the present pilot study.

\section{Results}

Eight one-page and ten two-page questionnaires were returned to sender because of incorrect addresses. The response rate to the one-page questionnaire was equal to that obtained after the first posting in the ECRHS in 19911992 (45\% versus $45 \%$, table 3 ), whereas the response rate to the two-page questionnaire was $38 \%$, showing a $7 \%$

Table 3. - Sample size, number of responders and response rate in the pilot study and in the first stage of the European Community Respiratory Health Survey (ECRHS-1)

\begin{tabular}{lrrc}
\hline & $\begin{array}{c}\text { Sample } \\
\text { size } \mathrm{n}\end{array}$ & $\begin{array}{c}\text { nesponders } \\
\mathrm{n}\end{array}$ & $\begin{array}{c}\text { Response } \\
\text { rate \% }\end{array}$ \\
\hline $\begin{array}{l}\text { Pilot study/short questionnaire } \\
\begin{array}{l}\text { Pilot study/extended } \\
\text { questionnaire }\end{array}\end{array}$ & 142 & 64 & 45 \\
$\begin{array}{l}\text { ECRHS 1 first contact (1992) } \\
\text { ECRHS }\end{array}$ & 14000 & 53 & 38 \\
\hline
\end{tabular}


Table 4. - Observed response rate to the one-page questionnaire in an average Italian centre in 1991-1992 and expected response rate when using the two-page questionnaire ${ }^{+}$

\begin{tabular}{|c|c|c|c|c|c|c|}
\hline \multirow[b]{2}{*}{ Contact } & \multicolumn{3}{|c|}{ One-page questionnaire (1991-92) } & \multicolumn{3}{|c|}{ Two-page questionnaire (expected) } \\
\hline & Target & Responders & $\begin{array}{c}\text { Cumulative } \\
\text { response rate \% }\end{array}$ & Target & Responders & $\begin{array}{l}\text { Cumulative response } \\
\text { rate } \%(95 \% \mathrm{CI})\end{array}$ \\
\hline \multicolumn{7}{|l|}{ Postal contact } \\
\hline First & 3000 & 1350 & 45 & 3000 & 1140 & $38(30-46)$ \\
\hline Second & 1650 & 360 & 57 & 1860 & 343 & $49(40-58)$ \\
\hline Third & 1290 & 330 & 68 & 1517 & 328 & $60(51-69)$ \\
\hline Total & 5940 & & & 6377 & & \\
\hline To be contacted by telephone & 960 & & & 1189 & & \\
\hline
\end{tabular}

*: a constant relative decrease in the two-page questionnaire was assumed in each wave. CI: confidence interval.

decrease in response (95\% confidence interval (CI) -1$15 \%)$. Both the questionnaires were correctly filled in by the responders.

In the first study, carried out in Italy [20], a response rate of $68 \%$ was reached using three postal contacts; a final response rate of $86 \%$ was obtained by means of telephone interviews with nonresponders. Table 4 compares the response rates obtained in an average Italian centre during the first study and those expected when using a two-page questionnaire. After three postal contacts a $60 \%(95 \% \mathrm{CI}$ $51-69 \%$ ) response rate was expected. The number of total posted contacts was expected to increase from 5,940 to 6,377 (a relative increase of $8 \%$ ) and the number of telephone calls from 960 to 1,189 (a relative increase of $24 \%)$.

On the basis of previous results, the relative increase in cost, when using the two-page questionnaire, is expected to be $9.7 \%$ (95\% CI $-1.3-21.3 \%)$, assuming that the cost of contact by post and by telephone is the same.

\section{Discussion}

The main aim of this paper was to present a new version of the questionnaire to be used in ECRHS stage 1 repeat study and to verify the impact of the length of the questionnaire on response rate. Although the addition of new questions to the single-page questionnaire did not affect the response rate, a slight reduction in participation was noted for the two-page questionnaire. Both the questionnaires were easily filled in by most of the subjects without errors.

Since no problem seems to arise from the addition of new questions to the single-page questionnaire, it is certainly worthwhile and advantageous to gain information on more symptoms and risk factors.

The administration of the two-page questionnaire by post resulted in a slightly decreased response rate compared with the one-page questionnaire. A response rate of $60 \%$ (95\% CI 51-69\%) would be expected to three mailings if the two-page questionnaire were sent. Since previous experience showed that the response rate to telephone interviews is very high, the lower level of postal response to the two-page questionnaire could be easily counterbalanced by intensified phone contact. Furthermore, it has been proven that the answers to the ECRHS screening questionnaire obtained by telephone interview agree strongly with those obtained by post [21] and have the same degree of reliability [22].
When using the two-page questionnaire, the cost of the survey would be expected to increase by $\sim 10 \%$ with respect to the use of the single-page questionnaire. As the second page of the questionnaire gives insight into the relatively unknown field of the social and economic burden of asthma, its use could be worthwhile despite the extra cost. According to their research interests, each centre participating in the new study will decide whether or not to use the two-page questionnaire.

List of principal participants: Co-ordinating Centre (London, UK). P. Burney, S. Chinn, C. Luczynska, D. Jarvis.

Project Management Group: P. Burney (Project leader); S. Chinn, C. Luczynska, D. Jarvis, F. Neukirch (Paris, France); B. Leynaert (Paris, France); J. Heinrich (Oberschleissheim, Germany); M. Wjst (Oberschleissheim, Germany); R. de Marco (Verona, Italy); C. Svanes (Bergen, Norway); J.M. Anto (Barcelona, Spain); J. Sunyer (Barcelona, Spain); C. Janson (Uppsala, Sweden); N.KuenzIi (Basle, Switzerland).

\section{References}

1. European Community Respiratory Health Survey. Variation in the prevalence of respiratory symptoms, selfreported asthma attacks, and use of asthma medication in the European Community Respiratory Health Survey (ECRHS). Eur Respir J 1996; 9: 687-695.

2. Janson C, Chinn S, Jarvis D, Burney P, for ECRHS. Physician diagnosed asthma and drug utilization in the ECRHS. Eur Respir J 1997; 10: 1795-1802.

3. Cerveri I, Zoia MC, Bugiani M, et al. Inadequate antiasthma drug use in the North of Italy. Eur Respir $J$ 1997; 10: 1-6.

4. de Marco R, Cerveri I, Bugiani M, Ferrari M, Verlato G. An undetected burden of asthma in Italy: the relationship between clinical and epidemiological diagnosis of asthma. Eur Respir J 1998; 11: 599-605.

5. Neukirch F, Pin I, Knani J, et al. Prevalence of asthma and asthma like symptoms in three French cities. Respir Med 1995; 89: 685-692.

6. Rona RJ, Chinn S, Burney PGJ. Trends in the prevalence of asthma in Scottish and English primary school children 1982-1992. Thorax 1995; 50: 992-993.

7. Tirimanna PRS, Vanschaych CP, Denotter JJ, et al. Prevalence of asthma and COPD in general practice in 1992 Has it changed since 1977? Br J Gen Pract 1996; 46: 277-281. 
8. Barnes PJ, Jonsson B, Klim JB. The costs of asthma. Eur Respir J 1996; 9: 636-642.

9. Nowak D, Volmer T, Wettengel R. Bronchial asthma - a cost of illness analysis. Pneumologie 1996; 50: 364-371.

10. Action asthma. The occurrence and cost of asthma. Cambridge Medical Publications, West Sussex, UK, 1990.

11. Boston Consulting Group. The cost of adult asthma in Canada. Princeton, USA, Communications Media for Education, 1993.

12. Krahn MD, Berka C, Langlois P, Detsky AS. Direct and indirect costs of asthma in Canada. Can Med Assoc J 1996; 154: 821-831.

13. Weiss KB, Gergen PJ, Hodgson TA. An economic evaluation of asthma in the United States. $N$ Engl J Med 1992; 326: 862-866.

14. Burney PGJ, Luczynska C, Chinn S, Jarvis D. The European Community Respiratory Health Survey. Eur Respir $J$ 1994; 7: 954-960.

15. The European Community Respiratory Health Survey. Medicine and Health. European Commission, Directorate-General XII, Office for Official Publication, L-2920 Luxembourg, 1994.

16. Siafakas NM, Vermeire $\mathrm{P}$, Pride NB, et al. Optimal assessment and management of chronic obstructive pulmonary disease (COPD). The European Respiratory Society Task Force. Eur Respir J 1995; 8: 1398-1420.

17. Burney P, Laitinen LA, Perdrizet S, et al. Validity and repeatability of the IUATLD (1984) Bronchial Symptoms Questionnaire: an international comparison. Eur Respir $J$ 1989; 2: 940-945.

18. Ackermann-Liebrich U, Leuenberger P, Schwartz J, et al. Lung function and long term exposure to air pollutants in Switzerland. Study on Air pollution and Lung Disease in Adults (SAPALDIA Team). Am J Respir Crit Care Med 1997; 155: 122-129.

19. Oglesby L, Kuenzli N, Monn C, Schindler C, Ackermann-Liebrich U, Leuenberger P, and SAPALDIA Team. Validity of annoyance scores to estimate long-term air pollution exposure in epidemiological studies. Am $J$ Epidemiol 1999 (in press).

20. de Marco R, Verlato G, Zanolin E, Bugiani M, Drane JW. Non response bias in EC Respiratory Health Survey in Italy. Eur Respir J 1994; 7: 2139-2145.

21. Galobardes MB, Castellsagué J, Sunyer J, Antò M. Assessing the administration method of a screening for respiratory symptoms. Eur Respir J 1993; 6 (Suppl. 17: 339s.

22. Galobardes B, Sunyer J, Antò JM, Castellsagué J, Soriano JB, Tobias A, and the Spanish Group of the European Asthma Study. Effect of the method of administration, mail or telephone, on the validity and reliability of a respiratory health questionnaire. The Spanish Centers of the European Asthma Study. J Clin Epidemiol 1998; 51: 875-881. 